\title{
A EXTRAÇÃO DO OURO NA AMAZÔNIA E SUAS IMPLICAÇÕES PARA O MEIO AMBIENTE
}

Frederico Luiz Silva Caheték*

\section{Condicionantes da mineração do ouro na Amazônia}

Para uma melhor compreensão do cenário deste setor produtivo caberia expor um resumo dos fatores que, de uma ou de outra forma, condicionam as suas atividades. Esta compreensão é, ao mesmo tempo, a da lógica das ações dos agentes diversos envolvidos na mineração.

Um destes fatores seria de ordem ambiental, ou, especificamente, geoclimático. Nesta dimensão as florestas apresentam-se como um dos grandes limitantes ao acesso às jazidas. Outro fenômeno interferente é o regime das chuvas pois impõe um período de suspensão das atividades. Influenciada por este regime mas que, por sua vez, também impõe limites às atividades encontra-se a configuração da rede hidrográfica. Além da referida importância da distribuição dos cursos d'água, o seu volume também determina uma maior ou menor intimidade com os "veios" de ouro.

Outros fatores condicionantes seriam de ordem econômico-financeira. No final da década de 70 e na década de 80 assistiu-se na Amazônia a uma nova corrida do ouro. Embora possa ser considerado um fenômeno multi-condicionado, seja por fatores regionais, nacionais e internacionais, ou, se preferir, conjunturais, há um fator considerado preponderante por diversos autores: a alta do preço do ouro no referido período no mercado internacional (Macmillan, 1993; Cleary, 1990).

\footnotetext{
* Este artigo foi escrito originalmente em 1995, estando, portanto, sujeito a desatualização em algumas informações.

** Biólogo, aluno do doutorado em Desenvolvimento Sustentável do Trópico Úmido - NAEA/UFPA. Pesquisador associado do NAEA vinculado ao Projeto Shift (Studies on Human Impact on Forests and Floodplains in the Tropics).
} 
Por último poderia se destacar as intervenções de ordem institucionais e políticos, destacando-se neste caso o aparato jurídico e os movimentos ambientalistas e de direitos humanos.

$\mathrm{Na}$ busca de informações sobre a extração do ouro na Amazônia e suas implicações ambientais, constatou-se que a maior parte das publicações consultadas compõe-se de estudos da problemática do mercúrio decorrente desta atividade. Seria interessante uma análise mais profunda do porquê desta ênfase dada ao mercúrio mas cabe também atenção às conseqüências da exploração aurífera na Amazônia resultantes da introdução e expansão da técnica de lixiviação do ouro através do cianeto. O emprego desta substância vem ganhando espaço na região através das atividades de mineradoras, sem que se tenha clareza das suas reações biogeoquímicas na realidade local. São questões em aberto para basear discussões sobre modelos de desenvolvimento na Amazônia.

\section{Técnicas da atividade de extração do ouro}

Em quase toda literatura especializada em mineração do ouro esta atividade geralmente é dada como ocorrendo por duas maneiras: garimpagem (setor informal) e mineração industrial. Essa classificação é mais freqüente nos veículos de divulgação tecnológica mas também aqueles voltados para as questões ambientais a adotam. De forma simplificada, a garimpagem é caracteriza principalmente pelos seguintes termos: 1) ênfase dada ao trabalho individual e de pequenas equipes (com cerca de oito homens); 2) há um predomínio dos instrumentos de trabalhos mais "rústicos" (manuais e semimecanizados), tais como a bateia, a picareta, a pá etc., apoiados ou não por maquinário a combustíveis fósseis, e 3) pelo uso do mercúrio na coleta de partículas de ouro. $\mathrm{Na}$ mineração industrial as características principais tomadas por base são: 1) utiliza-se como fonte de força predominante a energia elétrica; 2) opera-se com um conjunto mais sofisticado de máquinas e ferramentas; 3) compõe-se por uma equipe de trabalho mais complexa e hierarquizada (empresarial), e 4) empregam-se outra(s) substância(s) com maior capacidade de retenção de partículas finas de ouro.

A técnica de exploração em galerias de jazidas primárias é observável tanto na garimpagem quanto na chamada mineração industrial, sendo necessário nestes casos o uso de explosivos. Entretanto, na prática, muitas vezes fica difícil discernir as duas atividades, principalmente quando se trata de uma atividade empresarial de porte. Muitas mineradoras recorrem às duas formas de produção num mesmo local, podendo atuar durante um período com as duas técnicas combinadas, ou ainda de forma sucessiva, dependendo muito da história de exploração local.

Do ponto de vista da potencialidade de retenção de partículas mais finas, o processo da mineração industrial tem sido considerado mais eficiente pelas condições próprias de operacionalidade já descritas. Entretanto, é necessário um estudo estatístico comparativo atual entre a produção nos dois setores, pois o que tem se observado na história da mineração do ouro é que o setor informal, os garimpos, responde, com uma boa distância, pela maior parcela da produção do ouro no Brasil. Após o aumento do preço do ouro no mercado internacional e a decorrente explosão dos garimpos no Brasil a partir de 1979, a produção no setor informal chegou a corresponder a cerca de $90 \%$ do total produzido anualmente (Cleary, 1992). 


\subsection{A garimpagem ou a coleta baseada no mercúrio}

O garimpo pode ser de terra firme ou nos leitos dos cursos d'água. Em terra firme geralmente ocorre o desmonte de margens e encostas (os baixões) com fortes jatos d'água mas também se realiza o fracionamento do minério lavrado utilizando-se moinhos de martelo e centrífuga. Através de uma chupadeira o material resultante da lavagem com bico de jato é dragado e conduzido até uma caixa de madeira. A caixa, predominante em comprimento, é forrada com saco de aniagem ou carpete e possui taliscas transversais. Na parte superior da caixa e junto às taliscas é colocado o mercúrio para que forme uma amálgama com as partículas de ouro presentes. Parte do mercúrio não combinada com o ouro é perdida para o ambiente, como também o é a parcela amalgamada durante o processo de queima desta liga para purificar o ouro.

O caso da extração nos leitos de rios se dá através do bombeamento do material do fundo para a superfície de grandes balsas. O bombeamento pode ser feito através de dragas flutuantes com bombas de sucção de 10 a 12 polegadas possuindo comando hidráulico (Chaves e Albuquerque, 1994), ou por uma mangueira operada diretamente por um mergulhador no fundo. Após a triagem do ouro nas balsas o processo segue como na situação anterior, ou seja, amalgamento com o mercúrio e posterior queima deste.

\subsection{Setor formal: o uso predominante ou exclusivo do cianeto na exploração do ouro}

A extração de ouro através da técnica de lixiviação com o uso de cianeto, ou compostos de cianeto, tem como base o fenômeno de percolação. $\mathrm{O}$ minério é extraído em sua forma "bruta" (em combinação com outros elementos e/ou substâncias) da jazida e é conduzido para sofrer beneficiamento através da lixiviação, complementado ou não por outras técnicas.

A primeira etapa é denominada de lavra, e nela se coleta material onde está o minério. Esta pode ser realizada a céu aberto ou de forma subterrânea. Dentre os fatores considerados na definição do método de lavra estão: as características do depósito, isto é, dimensões, forma e profundidade; as características físicas, ou mecânicas, do material constituinte do depósito; as características hídricas e hidrológicas; certos fatores econômicos, tais como o teor do minério, custo de extração e escala de produção; os fatores ambientais, tais como, área de intervenção, receptores de poluição, emissões de matéria e energia etc.; a localização do depósito, principalmente do que se refere à disponibilidade de energia elétrica, mão-de-obra, infraestrutura urbana e de transporte etc. (CRDV, 1993).

Em outra etapa se dá o beneficiamento ou a lixiviação do ouro, a qual pode ocorrer de duas formas: Lixiviação de pilha e lixiviação de reservatório. A maior ou menor complexidade do beneficiamento depende de certos fatores, tais como: A granulometria do ouro nesse minério, grau de liberação passível de ser atingido com operações de cominuição economicamente viáveis; a composição mineralógica e associações de ouro com os minerais em questão; o teor médio de ouro no minério, massa de ouro contido na jazida, escala de produção e vida útil do empreendimento; a resposta às rotas convencionais de beneficiamento e recuperação global do processo; a localização da jazida, disponibilidade de água, energia e reagentes químicos; a complexidade do sistema, no que se refere a equipamentos e ao controle operacional; a natureza dos efluentes e controle ambiental; o investimento e custos operacionais (CRDV, 1993). 
A lixiviação de pilha possibilita o beneficiamento do minério de baixo teor, o qual mostra-se inviável do ponto de vista econômico para ser processado via lixiviação de reservatório. Na lixiviação de pilha o material é depositado em forma de montes e permanece a céu aberto. O local de deposição destas pilhas deve ser forrado com lona de PVC para torná-lo impermeável. Para racionalização da atividade deve se manusear várias pilhas simultaneamente, ou seja, enquanto uma está sendo montada, outra é lavada, uma outra é neutralizada etc. A duração aproximada do ciclo operacional completo por pilha é de 100 dias, devendo ser evitado o período de chuvas intensas. A solubilização do ouro contido nas pilhas se dá através da percolação de solução de cianeto de sódio. O ouro solubilizado será transferido e absorvido em filtros de carvão ativado. Através de um processo de eletrólise, o ouro será liberado e seguirá para fundição e montagem dos lingotes. Como forma de maximização produtiva, o carvão ativado pode passar por lavagem ácida e por uma regeneração térmica. Mas na prática o processo não ocorre assim, de forma tão aparentemente linear.

A Companhia Vale do Rio Doce é uma das empresas que explora o ouro em escala industrial, no município de Parauapebas, sul do Pará. Segundo informações locais, a reserva está estimada em 15 milhões de toneladas, apresentando um teor médio de 4,7 gramas de ouro por tonelada. A produção média mensal à época era de 450 quilogramas. As três formas no nível industrial que vem sendo usadas convencionalmente para o beneficiamento do minério aurífero são: a concentração gravítica; a lixiviação em tanques agitados (precedida ou não de concentração gravítica, concentração físico-química e/ou pré-oxidação); e a lixiviação em pilhas. No primeiro caso busca-se a recuperação do ouro liberado e partículas mistas com granulometria de até 0,104 mm (150 malhas), através do uso de jigs, mesas estáticas e mesas vibratórias. $\mathrm{O}$ concentrado gravítico pode ser submetido à fusão direta ou à amalgamação com mercúrio e retortagem da amálgama para a recuperação do ouro ligado a esta. Em algumas plantas se utiliza o mercúrio, ou se recorre ao método gravítico para processar os rejeitos deixados por garimpeiros. $\mathrm{Na}$ etapa dos circuitos hidrometalúrgicos, o ouro fino agregado ao minério, não recuperável através de concentração gravítica é solubilizado. O reagente utilizado é o cianeto de sódio, sob a forma de soluções diluídas $(0,05 \%$ a $0,1 \%)$. Outro reagente passível de ser utilizado é a tiouréia (a viabilidade técnico-econômica dessa rota ainda não foi estabelecida). Os circuitos de concentração físico-química, utilizando-se de flotação em células ou colunas, têm por objetivo reduzir a massa do material a ser processado, produzindo um concentrado de ouro a ser tratado em circuito hidrometalúrgico. De um modo geral, a flotação como etapa de concentração vem sendo utilizada para minérios contendo ouro agregado a sulfetos de metais básicos. Os circuitos de pré-oxidação são aplicáveis a minérios ditos refratários, isto é, aqueles que apresentam ouro no interior de partículas de sulfeto. Nesse caso, a oxidação dos sulfetos confere porosidade à partícula, permitindo, assim, que o ouro seja dissolvido através de cianetação em tanques com agitação (CRDV, 1993).

O cianeto é uma substância comercializada na forma sólida e com ela é preparada uma solução de cianeto de sódio $(\mathrm{NaCN})$ para que possa ser usado posteriormente. Calcula-se que para cada tonelada de minério consuma-se 250 gramas de cianeto para a dissolução do ouro nele presente. Além do cianeto, outras substância são necessárias na produção, tais como: soda cáustica, ácido clorídrico, cal virgem etc. O local onde ocorre o processo de lixiviação ou cianetação do ouro é denominado de planta. O processo envolve uma série de técnicas de reações químicas complexas e que por isso exige um rigoroso controle para não pôr em risco a vida dos operadores e, posteriormente, da fauna e flora adjacentes ao local. Ao contrário do mercúrio, o cianeto não se torna um processo acumulativo crônico nos tecidos dos 
organismos, mas pode matar de forma mais imediata se não for manuseado dentro dos rigores técnicos. Algumas regras básicas devem ser seguidas no local de manuseio do cianeto visando a segurança dos trabalhadores, tais como: uso de máscara com filtro especial; não se alimentar nem fumar; nunca ir para casa com roupa de trabalho contaminada; não misturar o cianeto com substâncias ácidas ou com sais ácidos pois reagem entre si e liberam vapores altamente tóxicos que podem ser letais (a mistura com a água também pode trazer problema dependendo da sua acidez); evitar o consumo de bebidas alcoólicas, pois as mesmas tornam os indivíduos mais sensíveis ao cianeto (Processos Projetos Minerais Ltda, 1993).

Granato (1986-1993), apresenta uma divisão bastante didática ao se referir às técnicas em si para lixiviação de minério de ouro. Comenta que as mesmas podem ser divididas basicamente em dois grupos principais: (1) lixiviação por percolação e (2) lixiviação por agitação. Recorrem-se às vias por percolação quando se trata de pequenos depósitos de minérios, de rejeitos estocados de minas ou de minérios de baixo teor. São os custos mais baixos de instalação e operação para a extração do ouro nestas condições que tornam o processo viável do ponto de vista econômico. Entretanto, as recuperações alcançadas são inferiores àquelas por agitação. Os processos por percolação ocorrem através das já mencionadas pilhas, em montes, e também em tanques. Os efluentes gerados podem ser reciclados, exigindo-se numa dada medida um tratamento químico antes da sua liberação para que não poluam o meio ambiente. No caso da lixiviação por agitação torna-se necessário uma maior taxa de investimentos no sistema, mas é possível recuperar-se níveis de até $100 \%$ do ouro contido no minério. Em contrapartida, a carga de poluentes gerada é geralmente mais alta. Tradicionalmente os processos por agitação ocorrem através da lavagem em contracorrente e precipitação com zinco, ou com carvão ativado. Neste último encontram-se os processos de carvão em polpa, carvão na lixiviação e carvão em colunas. Através de reações químicas do zinco ( $\mathrm{Zn}$ ) no material lixiviado ocorre a liberação do ouro $(\mathrm{Au})$, ligado a compostos de cianetos, conforme representação abaixo:

$$
2 \mathrm{NaAu}(\mathrm{CN})_{2}+\mathrm{Zn} \leftrightarrow 2 \mathrm{Au}^{\mathrm{O}}+\mathrm{Na}_{2} \mathrm{Zn}(\mathrm{CN})_{4}
$$

Para se realizar a contento outras reações, visando otimizar a operação, utilizam-se sais de chumbo.

Numa etapa posterior, ou na primeira etapa de recuperação propriamente dita, o ouro ficará retido em carvão ativado. O carvão originado da casca do coco é considerado o mais adequado pelo seu alto poder de retenção e sua alta resistência à abrasão. O modo como este carvão será empregado dependerá da natureza da lixívia. Por exemplo, quando da percolação resulta uma lixívia isenta de partículas sólidas em suspensão, recorre-se ao processo de carvão ativado disposto em colunas. Constata-se que a maioria da lixívia produzida em operações por percolação encontra-se nesta condição. A solução contendo ouro é forçada a passar através de colunas contendo cartuchos de carvão ativado. Este processo é denominado de adsorção. $\mathrm{O}$ processo inverso, ou seja, o descarregamento, é denominado tecnicamente de dessorção, o que ocorre a partir do momento em que o carvão ativado atinge a sua capacidade máxima de retenção. Segundo o autor, as reações ao nível químico observadas na eletrorrecuperação são as seguintes:

$$
\begin{aligned}
& 4 \mathrm{OH}^{-} \leftrightarrow \mathrm{O}_{2}+2 \mathrm{H}_{2} \mathrm{O}+4 \mathrm{e}^{-} \\
& 2 \mathrm{H}_{2} \mathrm{O}+2 \mathrm{e}^{-} \leftrightarrow \mathrm{H}_{2}{ }^{\nearrow}+2 \mathrm{OH}^{-}
\end{aligned}
$$




$$
\mathrm{Au}(\mathrm{CN})^{-}{ }_{2}+\mathrm{e}^{-} \leftrightarrow \mathrm{Au}^{0}+2 \mathrm{CN}^{-}
$$

O ouro extraído do carvão ativado é repassado para uma solução que será submetida a um outro processo denominado de eletrólise. A eletrorrecuperação está condicionada principalmente pelos seguintes aspectos: 1) intensidade de circulação da solução; 2) temperatura da solução; 3) densidade de corrente; 4) composição da solução; 5) voltagem. Para a realização da última etapa do processamento, denominada de refino, deve haver uma prépurificação pois, juntamente com o ouro, encontram-se outros minérios agregados. São exemplos destes últimos, a prata, o chumbo, o zinco, o cobre, o mercúrio etc.

\section{Impactos}

Assim como ocorre na extração de outros minérios, na do ouro também são provocados impactos consideráveis, seja no nível fisionômico, no químico, no biológico, ou nas populações humanas. Conforme comentado anteriormente, dentre os danos resultantes da mineração do ouro, dá-se maior destaque aos referentes ao mercúrio. Mas como se pode ver em seguida, são inúmeros os problemas, os quais merecem uma maior dedicação para finalizálos ou mitigá-los.

\subsection{Alterações físicas ou paisagísticas}

Dentre os efeitos físicos de grande importância nos casos dos garimpos estão os desmatamentos resultantes da construção de pistas de pouso, dos acampamentos, das currutelas e do desmonte de barrancos, às margens; alteração física também considerável é dos leitos dos cursos d'água pela atividade direta e diária do garimpeiro mergulhador.

Por sua vez, os desmontes de barrancos e sucção dos leitos provocam modificações profundas em ecossistemas aquáticos e ribeirinhos, tal como a liberação de grandes volumes de silte e argila que provocam alterações nas condições físico-químicas da água. Um dos parâmetros de maior importância que sofre modificação é a luminosidade, a qual interfere diretamente na atividade da comunidade fitoplanctônica que compõe a base produtiva da teia alimentar.

Outros efeitos dos desmontes são o assoreamento e/ou alteração nos cursos naturais das águas, levando à inundação de áreas até então emersas e a formação de poças d'água isoladas. Quase sempre estes novos ambientes isolados, pela ausência de predadores, tornamse propícios para a proliferação de larvas de insetos, dentre as quais as do gênero transmissor da malária.

Por conta da agricultura praticada em certos locais nos períodos de chuva ocorre a introdução de espécies vegetais, até então estranhas ao local onde havia cobertura arbórea. Com relação à fauna, as três maiores tendências seriam: 1) o afastamento ou mesmo o desaparecimento de espécies regionais nativas, por conseqüência do ruído mas principalmente pela pressão da caça e pesca intensas; 2) a aproximação nas áreas de roças de espécies que se alimentam dos produtos delas; 3) a introdução de espécies domésticas.

A emissão dos gases, e o ruído intermitente do maquinário (geradores, compressores, dragas) e de veículos nas áreas servidas por estradas, também configuram-se como outros elementos de perturbação no ambiente. 
Ainda neste contexto de impactos na estrutura física estão as galerias abertas à base de dinamite para a extração do ouro primário, as quais freqüentemente provocam danos na superfície quando desmoronam.

\subsection{Os impactos químicos e suas relações com o nível biológico}

$\mathrm{O}$ aspecto químico refere-se tanto às substâncias de origem antrópica lançadas diretamente, quanto os compostos químicos delas derivados. É o caso, por exemplo, do sabão em pó e detergente usados na lavagem das caixas de coleta e de louças, e do sabão em pedra usado para lavagem de louças, roupas e na higiene pessoal.

O vazamento de combustíveis fósseis (gasolina, querosene e óleo diesel e graxas empregados no maquinário também configuram-se como outros elementos de poluição do ambiente.

Este material de limpeza bem como os combustíveis podem causar danos a nível mais imediato mas também a médio e longo prazos, dependendo do potencial de acúmulo deles nos sistemas hídricos.

Pelas proporções dos efeitos potencializados no uso do mercúrio e do cianeto na coleta do minério de ouro, estas duas substâncias são estudadas com maior acuidade pelos diversos setores envolvidos na mineração, sejam os centros de pesquisas, agências de saúde, órgãos governamentais etc.

\subsection{O caso do mercúrio}

Sem dúvida, a maior ênfase dos impactos de ordem química é dada ao problema do mercúrio em detrimento destas outras substâncias liberadas, ou mesmo dos efeitos sociais danosos resultantes da exploração do ouro na Amazônia. Seja como for, a problemática do mercúrio nesta região tem recebido, principalmente na última década, apoio de governos e das mais diversas instituições para a sua pesquisa, levando a uma produção de conhecimento não encontrada para nenhum outro problema de poluição relacionado com a extração do ouro.

As informações sobre o volume de mercúrio lançado no meio ambiente amazônico são controversas. Os números sobre os volumes de origem antrópica não coincidem e além disto joga-se com a possibilidade de que as queimadas liberem grande parte do mercúrio que atingem os cursos d'água. Barbosa (s/d), estima em cerca de $200 \mathrm{~T} / \mathrm{ano}$ de $\mathrm{Hg}$ entrando na Amazônia, resultantes da garimpagem. Pfeiffer e Lacerda (1988), estimaram uma perda média anual de 96 toneladas de mercúrio para esta região. Deste total, $45 \%$ entravam sob a forma de metal nos rios, e 55\% entravam para a atmosfera em forma de vapor. Já para Forsberg (s/d), ocorreu uma perda média anual de 249 toneladas durante o período que vai de 1984 a 1986. Outros autores calcularam para o período de 1980 a 1987 uma perda de 1,8 tonelada, ou 150 toneladas médias anuais (Silva et al., 1989).

O comportamento do mercúrio após ser introduzido no ambiente também sido alvo de investigações. Estes estudos são bem mais freqüentes no exterior mas alguns modelos explicativos para a Amazônia já foram tentados. Lacerda (1992), formulou um modelo considerando nele como processos dominantes o tempo de residência do vapor de mercúrio na atmosfera, a interação do mercúrio com a ciclagem de nutrientes e a sua complexificação e transporte no sistema hídrico. 
Pesquisa sobre a contaminação do mercúrio em dois garimpos do Estado do Pará comparou os graus de concentrações entre os mesmos através de sedimento e da água. Um dos garimpos estudado foi o de Cachoeiro, localizado na fronteira Pará/Maranhão, a 20 quilômetros do rio Gurupi. O outro foi o garimpo do Cumaru, situado no município de Redenção, no sudeste do Pará. Os resultados demonstraram situações distintas entre as duas áreas, quanto à contaminação por mercúrio (Ramos e Costa, 1992).

A pedido da Companhia Vale do Rio Doce - CVRD foi feito um estudo para avaliar os níveis de contaminação de mercúrio na área de influência do Projeto Carajás, Pará, decorrente da ação de garimpos na mesma. O estudo abrangeu cinco áreas de garimpos em atividade (Grota da Cruz, Esquecido e Aquiri, na bacia de drenagem do rio Itacaiúnas; Serra Peladinha e Serra Dourada, na bacia de drenagem do rio Parauapebas) e três desativados (Gameleira, Água Clara e Salobo). As amostras de água fluvial, peixe, sedimento e cabelo foram coletadas em duas etapas: Uma delas em outubro, época caracterizada por extrema vazante e intensa atividade, o que significa menor capacidade dos rios de dispersão e diluição; a outra foi feita em junho, época de cheias e atividades garimpeiras praticamente ausentes, traduzindo-se em maior diluição e dispersão de materiais. O único material onde não detectou-se contaminação foi no cabelo (Fernandes et al., s/d).

Três trabalhos mais recentes tratando de aspectos geoquímicos, biológicos e sociais foram realizados na bacia do Tapajós, Pará, acrescentando novos dados para a região. Um deles, o "Projeto Canga-Tapajós", tratando de aspectos bio-geoquímicos e sociais, foi iniciativa do governo do Estado, através da sua Secretaria de Indústria, Comércio e Mineração SEICOM - na região do Garimpo do Rato (Relatório, 1992). O segundo foi o "Projeto Itaituba", o qual se propôs basicamente traçar o perfil de saúde da comunidade do Garimpo do Rato, observando as relações entre o estado geral e as condições de trabalho (Grupo de Saúde do Laboratório de Ecologia Humana e Meio Ambiente do Instituto Evandro Chagas, 1993, Relatório). O terceiro, denominado "Mercury Contamination in the Brazilian Amazon" foi uma ação interinstitucional, envolvendo Instituições da Europa, Estados Unidos e Brasil, tendo sido administrado pela ONG "Grupo de Estudos e Defesa do Baixo Amazonas - CE". Este trabalho teve como áreas de amostragens os seguintes locais: Cuiú-Cuiú, Crepori, Jacareaganga e Itaituba (Thornton $e t$ al., s/d.).

Publicação atual sobre a contaminação de mercúrio no lago formado pela UHE de Tucuruí/Pará, mostrou dados preocupantes sobre aquela situação. Foi analisada neste trabalho uma considerável diversidade de materiais, tais como, amostras de solo, vegetais (Eichornia crassipes, Salvinia auriculata, Scirpus cubensis), animais aquáticos (peixes, jacarés, tartarugas) e terrestres (capivara), sedimentos, e cabelo humano. Os garimpos de ouro com uso de mercúrio são comuns nesta área, estando a mesma, inclusive, sob a influência do garimpo de Serra Pelada. (Lodenius, 1992).

Além do já citado, um outro estudo dissertativo tratou da contaminação mercurial nos rios Crepori e Marupá, sudeste do Pará, ambos pertencentes à bacia do Tapajós. O autor analisou água, sedimentos de fundo e em suspensão, além de rejeitos de garimpagem dos rios referidos. Parâmetros como o pH e carbono orgânico foram utilizados nas discussões dos processos de retenção e transporte de mercúrio no ambiente aquático (Brabo, 1992).

No garimpo de Serra Pelada muito mercúrio já foi perdido, seja na cratera formada na cava principal, seja nos vilarejos nas imediações da mesma, mesmo considerando-se o período 
de proibição do seu emprego. Em 1985 calculava-se uma população só neste garimpo em torno de 100 mil trabalhadores (Cleary, 1990). Um dos trabalhos sobre contaminação mercurial neste garimpo analisou a distribuição do mercúrio total em solos e sedimentos (Neto, H. A. In: Hacon, 1992).

No Estado de Rondônia foi realizada uma pesquisa sobre concentração de mercúrio em diversos ecossistemas, sendo os dados obtidos comparados com os resultados dos garimpos do Rio de Janeiro. A concentração de mercúrio total em Rondônia foi medida na água, sedimento e peixes, coletados ao longo do rio Madeira, de tributários deste, e cursos d'água florestais (Pfeiffer et al., 1989).

A ênfase dada ao mercúrio se deve, principalmente, pelo fato de que os seus efeitos podem surgir muito tempo depois de cessada a sua liberação através da teia alimentar (peixes, por exemplo) mas também pode ser imediatamente incorporado através dos alvéolos pulmonares ou dispersado na atmosfera quando se encontra sob a forma de vapor. Nesta última situação o mercúrio será facilmente reintroduzido em novos ambientes através das chuvas. Uma questão fundamental no estudo do comportamento do mercúrio no meio ambiente é o das suas transformações. Após entrar no meio aquático, o mercúrio pode passar à forma iônica e depois sofrer o processo de biometilação, gerando os derivados orgânicos: monometilmercúrio (ou apenas metilmercúrio) e dimetilmercúrio $\left(\mathrm{CH}_{3} \mathrm{Hg}^{+}\right.$e $\mathrm{CH}_{3} \mathrm{Hg} \mathrm{CH}_{3}$, respectivamente). É o metilmercúrio a forma mais tóxica para os organismos vivos, uma vez que possui grande poder de mobilidade, atravessa facilmente as membranas biológicas e tem grande afinidade com estruturas moleculares que são básicas nas proteínas. O modelo mais tradicionalmente aceito na explicação do surgimento do metilmercúrio no meio aquático indica a ação de microorganismos como o fator diretamente responsável. Os microorganismos atuam sobre o mercúrio contido principalmente nas camadas mais superficiais dos sedimentos orgânicos mas também sobre a matéria orgânica suspensa na coluna d'água (World Helth Organization, 1976). Pfeiffer et al.(1990), em estudo sobre a questão dos garimpos, referindo-se especificamente à questão do mercúrio, afirmaram que o processo de metilação deste metal pode ocorrer fora de organismos vivos, bastando estarem presentes os ácido fúlvicos e húmicos em altas concentrações mas que este processo em quase sua totalidade é biologicamente mediado. Segundo a World Helth Organization (1989), a produção do metilmercúrio e sua difusão para o meio aquático é apenas um dentre os seis mecanismos de defesa de microorganismos como reações aos íons metálicos que lhe invadem. De outra forma, embora minoritária, há uma corrente de opinião na comunidade científica que considera a ação da luz solar (raios ultravioleta) como o fator preponderante na produção do metilmercúrio.

Além das pesquisas apoiadas na química para interpretar os problemas ambientais surgidos com o lançamento do mercúrio, existem experimentos que buscam analisar os efeitos diretos sobre animais. Por exemplo, Doudoroff et al. (1953), realizaram uma revisão crítica das publicações que tratam dos efeitos sobre peixes de subprodutos industriais e de seus componentes contendo mercúrio e outros metais lançados no meio ambiente. 


\subsection{O caso da contaminação com o cianeto}

Para uma melhor compreensão dos eventuais efeitos do cianeto, ou dos seus derivados nos processos de lixiviação, sobre a fauna e a flora, torna-se necessário um conhecimento básico da sua química.

O cianeto, ou melhor dizendo, os cianetos, possuem em comum o grupamento ciano, representado por $\mathrm{C} \equiv \mathrm{N}$. O íon cianeto $\left(\mathrm{CN}^{-}\right)$, que é a forma denominada livre, é uma espécie química que pode ser encontrada com freqüência em efluentes resultantes da extração do ouro e que se combina com elementos químicos deste ou de outro meio, formando complexos tóxicos. Os compostos mais simples, tal como a molécula $\mathrm{HCN}$ podem passar facilmente à condição de gás cianídrico durante elevação da temperatura e diminuição do pH (ácido). É um gás altamente tóxico e pode ser letal, dependendo da concentração ingerida.

Tabela 1 - Relação de cianocomplexos metálicos e suas estabilidades relativas (segundo Scott \& Ingles, 1981)

\begin{tabular}{|c|c|c|}
\hline \multicolumn{2}{|c|}{ Caracterização } & Principais Compostos \\
\hline \multicolumn{2}{|c|}{ Cianetos livres } & $\mathrm{CN}^{-}, \mathrm{HCN}$ \\
\hline Compostos simples & \begin{tabular}{|l}
$\begin{array}{l}\text { Prontamente } \\
\text { solúveis }\end{array}$ \\
Relativamente \\
insolúveis
\end{tabular} & $\begin{array}{c}\mathrm{NaCN}, \mathrm{KCN}, \mathrm{Ca}(\mathrm{CN})_{2}, \mathrm{Hg}(\mathrm{CN})_{2}, \\
\mathrm{Zn}(\mathrm{CN})_{2}, \mathrm{Cd}(\mathrm{CN})_{2}, \mathrm{CuCN}, \mathrm{Ni}(\mathrm{CN})_{2}, \mathrm{AgCN}\end{array}$ \\
\hline \multicolumn{2}{|c|}{ Complexos fracos } & $\mathrm{Zn}(\mathrm{CN})={ }_{4}, \mathrm{Cd}(\mathrm{CN})^{-}{ }_{3}, \mathrm{Cd}(\mathrm{CN})={ }_{4}$ \\
\hline \multicolumn{2}{|c|}{ Complexos moderadamente fortes } & $\mathrm{Cu}(\mathrm{CN})^{-}{ }_{2}, \mathrm{Cu}(\mathrm{CN})={ }_{3}, \mathrm{Ni}(\mathrm{CN})={ }_{4}, \mathrm{Ag}(\mathrm{CN})={ }_{2}$ \\
\hline \multicolumn{2}{|c|}{ Complexos fortes } & $\mathrm{Fe}(\mathrm{CN})_{6}{ }^{-}, \mathrm{Co}(\mathrm{CN})_{6}{ }^{-}$ \\
\hline
\end{tabular}

Ao se combinar com certos elementos químicos metálicos os cianetos formam complexos que podem ser instáveis e estáveis, respectivamente fracos e fortes. Quanto mais estáveis forem estes cianocomplexos, menos tóxicos os efeitos para o meio ambiente (Castro, 1992). Como exemplos de complexos fracos citam-se os de cádmio, $\mathrm{Cd}(\mathrm{CN})_{2}$; de zinco, $\mathrm{Zn}(\mathrm{CN})_{2}$ etc. São exemplos de complexos fortes os de níquel, $\mathrm{Ni}(\mathrm{CN})_{2} .4 \mathrm{H}_{2} \mathrm{O}$; de ouro, $\mathrm{Au}(\mathrm{CN})$; de prata, $\mathrm{AgCN}$; e os de ferro, $\mathrm{Fe}(\mathrm{CN}){ }^{4-}{ }_{6 .}$ A seguir uma relação de cianocomplexos metálicos com respectivas estabilidades (Tabela 1).

O cianeto pode também realizar reações químicas com compostos orgânicos. É o caso, por exemplo, da reação do cianeto de potássio com a glicose, em presença da água. A representação química desta reação é a seguinte:

$$
\mathrm{C}_{6}\left(\mathrm{H}_{2} \mathrm{O}\right)_{6}+\mathrm{KCN}+2 \mathrm{H}_{2} \mathrm{O} \rightarrow \text { OH.CH}(\mathrm{CH} . \mathrm{OH})_{5}: \mathrm{CO}_{2} \mathrm{~K}+\mathrm{NH}_{3}
$$


Tabela 2 - Concentração de algumas substâncias que causam efeitos tóxicos agudos a organismos aquáticos (Ingles \& Scott, 1988) com seus respectivos padrões de emissão de efluentes (Granato, 1993).

\begin{tabular}{|l|c|c|c|}
\hline \multicolumn{1}{|c|}{ Substância } & $\begin{array}{c}\text { Concentração para } \\
\text { efeito agudo (mg/l) }\end{array}$ & $\begin{array}{c}\text { Padrão de emissão } \\
\text { Cetesb -SP (mg/l) }\end{array}$ & $\begin{array}{c}\text { Padrão de emissão } \\
\text { Feema - RJ (mg/l) }\end{array}$ \\
\hline Cianeto & 0,10 & 0,2 & 0,2 \\
\hline Cádmio & 0,065 & 0,2 & 0,1 \\
\hline Chumbo & 0,45 & 0,5 & 0,5 \\
\hline Alumínio & 3,9 & - & 3,0 \\
\hline Cobre & 0,009 & 1,0 & 0,5 \\
\hline Cromo VI & 0,037 & 0,1 & 0,5 \\
\hline Fenol & 62,0 & 0,5 & 0,2 \\
\hline Ferro & 9,6 & 15,0 & 15,0 \\
\hline Nitrogênio Amoniacal & 85,1 & - & 5,0 \\
\hline Sulfeto & 0,02 & - & 1,0 \\
\hline Zinco & 0,5 & 5,0 & 1,0 \\
\hline Organoclorados & 0,01 & - & - \\
\hline
\end{tabular}

Além das ameaças mais imediatas representadas pelos gases resultantes da própria manipulação industrial já mencionada - efeito agudo ou imediato - estes complexos de cianetos representam também riscos potenciais para o meio ambiente se não forem tratados antes da liberação dos efluentes (embora investigadores afirmem que na prática essa avaliação seja difícil). Apontam-se os corpos d'água como o principal meio atingido pelos contaminantes. Não apenas as águas superficiais que servem de hábitat para peixes e outras formas vivas, ou como fonte de abastecimento urbano, mas também os lençóis freáticos. Estes corpos d'água subterrâneos que já vêm sendo ameaçados pela infiltração de combustíveis de origem fóssil (gasolina, óleo diesel), água de esgotos, agrotóxicos, fertilizantes e outros compostos químicos, agora se encontram diante de um novo risco com a expansão das empresas exploradoras de ouro através do cianeto. Órgãos públicos no país ligados ao controle ambiental da poluição já determinaram os valores máximos de concentração para efeito agudo, bem como padrões de emissão para o cianeto e outros elementos químicos (Tabela 2).

\subsection{Impactos sócio-econômicos e políticos}

Acidentes de trabalho, tráfico de drogas, prostituição/exploração de menores, crimes, comércio ilegal de armas. Estes são os problemas de destaque referentes às dimensões humanas acima referidas nas regiões mais influenciadas pela mineração aurífera.

A venda ilegal de mercúrio e o seu uso abusivo são outros graves problemas que merecem atenção rigorosa por parte do governo federal. Para que se tenha uma idéia, num trabalho sobre a produção aurífera na Amazônia durante o período de 1980 a 1987 calculou-se uma demanda de mercúrio equivalente para tal produção em torno de 1,8 tonelada. Os registros oficiais sobre o volume de mercúrio importado neste mesmo período foi de 1,4 tonelada para as necessidades no país inteiro. Seus autores concluíram que estava havendo uma entrada ilegal de mercúrio no Brasil para ser usado nos garimpos (Silva et al., 1989).

Estudos sobre as condições de saúde em garimpos de ouro na Amazônia objetivou construir um modelo explicativo do processo saúde/doença do garimpeiro enquanto grupo social. Foi investigado o perfil de morbi-mortalidade, sendo dado destaque para a malária, a 
intoxicação por mercúrio e a violência. Também foi verificada a gênese da mão-de-obra. A conclusão a que chegou a autora foi que o problema do garimpo é de natureza política (Couto,1993).

Outro estudo na área de saúde na Amazônia incluindo contaminação de mercúrio foi realizado como tema dissertativo de mestrado. Dentre outros aspectos, o autor fez uma avaliação das políticas de Estado para a saúde desde as grande campanhas de combates às doenças endêmicas no Norte do país e apresentou um quadro sobre a contaminação mercurial no garimpo de Crepori/Pará (Amoras, 1991).

\subsection{Garimpos em terras indígenas}

Além dos problemas de conflitos tradicionalmente encontrados quando ocorre este tipo de atividade em terras indígenas, que podem até mesmo levar a extermínio físico e outros efeitos mais imediatos, acrescentam-se agora os decorrentes da introdução do mercúrio. A Amazônia é uma região onde este fato vem ocorrendo nas últimas décadas. Pelo menos em dois Estados já foram realizados estudos de acompanhamento de eventuais efeitos da presença do mercúrio sobre as populações indígenas: Pará e Roraima, os quais são mencionados em seguida.

Um trabalho na área de saúde, feito dentro do "Programa de Epidemiologia e Controle de Endemias da ENSP”, voltou-se para áreas específicas no Estado do Pará. Os locais foram os garimpos de Cumaru e Cachoeiro, e a Reserva Indígena Gorotire, dos Caiapós. Embora os autores tivessem registrado na época que os Caiapós não garimpavam, eles os incluíram na amostragem por viverem às margens do rio Fresco, polú́do pelo garimpo de Maria Bonita. No garimpo de Cumaru foram aplicados questionários com dados de identificação, história ocupacional, social e morbidade referida. Apesar da suspeita de contaminação dos funcionários locais da Caixa Econômica Federal durante a queima da amálgama, não foram retiradas amostras deles. No período de contato com a equipe deste programa mencionado não haviam dados sobre taxas de contaminação de mercúrio.

A primeira iniciativa registrada em Roraima para verificar efeitos da contaminação de mercúrio em populações humanas e meio ambiente foi uma ação conjunta entre técnicos da Faculdade de Medicina da Universidade de Kumamoto, do Japão, e membros da então comissão pró-criação do parque indígena Ianomâmi. O trabalho constou da análise de amostras de cabelo de populações indígenas. Seus resultados demonstraram na época valores de contaminação de mercúrio abaixo dos níveis máximos de tolerância pelo organismo. Outro passo foi dado pelo autor deste trabalho, numa ação conjunta entre a Universidade Federal de Roraima, o Instituto Nacional de Pesquisas da Amazônia e a Fundação Nacional de Saúde. O material coletado neste projeto constou de amostras de cabelo, solo, plantas e animais, obtidos no Parque Ianomâmi e na capital de Roraima (em fase de análise).

Considerando-se o potencial de contaminação do mercúrio a médio e longo prazos, e ainda o fato de que os garimpos clandestinos não persistem em áreas indígenas, torna-se necessário um acompanhamento permanente sobre valores das taxas de mercúrio nas populações destas áreas. 


\section{Alternativas}

\subsection{Iniciativas para o controle e/ou substituição do mercúrio e resolução de outros problemas da mineração aurífera}

Antes de se passar à questão de modelo(s) alternativo(s) seria importante expor um resumo de contribuições já lançadas por diversos autores. Tais contribuições resultam de vários estudos em campo e de discussões em encontros tratando dos problemas das atividades de produção de ouro. Visam basicamente a mitigação ou a prevenção dos impactos para áreas requeridas e àquelas já em exploração mas não perturbadas, bem como o controle e a reversão da poluição e dos danos sociais em áreas antigas ou recentemente alteradas. As propostas mais divulgadas estão relacionadas no quadro a seguir.

Quadro 1: Sinópse de propostas divulgadas através da literatura especializada visando solucionar os problemas afetos à mineração aurífera ${ }^{1}$

\begin{tabular}{|c|c|c|c|c|}
\hline \multirow[t]{2}{*}{ Propostas } & \multicolumn{4}{|c|}{ Proponentes } \\
\hline & $\mathrm{Ce}^{3}$ & Poconé ${ }^{4}$ & $\begin{array}{l}\text { Semin. }{ }^{5} \\
\text { Cetem }^{6}\end{array}$ & MacMillan \\
\hline 1) Programa de educação ambiental ${ }^{9}$ & $\mathrm{X}$ & & $\mathrm{X}$ & $\mathrm{X}$ \\
\hline 2) Tecnologias alternativas ${ }^{10}$ & $\mathrm{X}$ & $\mathrm{X}$ & $\mathrm{X}$ & $\mathrm{X}$ \\
\hline $\begin{array}{l}\text { 3) Políticas de controle para a } \\
\text { garimpagem }{ }^{11}\end{array}$ & $\mathrm{X}$ & & $\mathrm{X}$ & \\
\hline $\begin{array}{l}\text { 4) Pesquisa na área de toxicologia } \\
\text { ambiental }{ }^{12}\end{array}$ & $\mathrm{X}$ & & & \\
\hline 5) Regeneração de áreas mineradas ${ }^{13}$ & & & $\mathrm{X}$ & \\
\hline $\begin{array}{l}\text { 6) Programa de análise crítica dos } \\
\text { impactos sócio-econômicos }{ }^{14}\end{array}$ & $\bar{X}$ & & & \\
\hline $\begin{array}{l}\text { 7) Política agrícola e de saúde para os } \\
\text { pequenos produtores }{ }^{15}\end{array}$ & $\mathrm{X}$ & & $\mathrm{X}$ & \\
\hline 8) Otimização de gerenciamento ${ }^{16}$ & $\mathrm{X}$ & & $\mathrm{X}$ & \\
\hline
\end{tabular}

\subsection{A propósito de um modelo}

Para se iniciar uma discussão buscando-se soluções para os problemas ambientais identificados nas áreas de mineração do ouro na Amazônia pressupõe-se algumas questões como sendo básicas. Uma delas seria investigar a real extensão da presença crescente de empresas na exploração do ouro nesta atual década. Outra seria o entendimento do que poderia estar ocorrendo no ambiente a partir do uso de cianeto em áreas onde o mercúrio já foi lançado.

\footnotetext{
1 Por uma questão de ordem prática optou-se por um quadro sinóptico, o que significa que as propostas relacionadas por temas gerais na coluna à esquerda, e detalhadas abaixo do quadro, resumem um conjunto de idéias de iniciativa individual ou de grupos.
} 
Da forma como o ouro é extraído na Amazônia, em termos de tecnologia, meio ambiente, economia e sociedade, é possível considerar este ramo de atividade como "sustentável"? Ou antes, o que seria "sustentabilidade" ou "sustentabilidade econômica" na mineração do ouro na Amazônia?

Pode se falar em um modelo sustentável para a atividade de extração do ouro, ou seja, sustentabilidade na exploração econômica de uma fonte de recurso não renovável? Ou talvez de um modelo de gerenciamento das futuras explorações com base nas reservas previstas?

Uma vez que falar em "modelo alternativo" implica propor mudança a algo já existente, obviamente depreende-se que um passo inicial seria uma análise crítica rigorosa de problemas específicos das regiões de produção do ouro. Pelo menos certas regiões de quatro Estados amazônicos parecem representativas: Rondônia (Porto Velho/rio Madeira), Roraima (savanas do norte e florestas do Parque Indígena Ianomâmi), Pará (bacia do rio Tapajós, Viseu), Amapá (Lourenço/Caciporé). Alguns parâmetros elementares para instrumentalizar esta avaliação seriam verificados nos períodos anteriores, durante e posteriores às corridas do ouro. Em outros casos se procederia da coleta de dados atualizados para embasar projeções. Destacam-se os dados seguintes: taxas de crescimento populacional e econômico, movimentos migratórios, distribuição de renda, origens dos recursos alocados na mineração, destino da renda obtida neste ramo de atividade, evolução das paisagens, índices criminais com respectivas causa mortis, prospecções geológicas, políticas mineral e ambiental vigentes etc. De outro modo, pensar em alternativas ao atual quadro significa também incluir métodos analíticos que, além de serem mais eficientes em termos de custo e tempo, devem dar conta da interpretação do que poderá estar ocorrendo com a introdução do cianeto em áreas já contaminadas com mercúrio.

\subsection{Técnicas de análises do material contaminado com mercúrio}

Atualmente no Brasil os centros capacitados para análise da concentração do mercúrio total estão nos Estados do Pará, Amazonas, Rio de Janeiro e Brasília. Mas, no que se refere ao metilmercúrio (mercúrio orgânico), apenas Brasília e Rio de Janeiro possuem condições atualmente de realizar a determinação deste sal de mercúrio. Há estudos especificamente voltados para o aprimoramento de técnicas de análises já existentes, seja para ampliar a sensibilidade dos aparelhos para a leitura, seja para ampliar a capacidade de análise dos diversos materiais contaminados. É necessário adequar métodos que já possuem grande poder na detectação de partículas ínfimas mas que são lentos e dispendiosos. Dentre métodos adotados para a determinação do mercúrio, citam-se: Mercúrio total em água (CETESB, 1989); Mercúrio total em peixe (Campe e Claeys, 1978; Loule, 1983); Mercúrio total em urina (Lindstedt, 1970); Mercúrio total em matéria orgânica, em pequenas concentrações (Johnson et al., 1968); Mercúrio orgânico em produtos agrícolas (Pickard e Martin, 1960); Mercúrio total e mercúrio orgânico em materiais biológicos (Magos, 1973); Mercúrio total e mercúrio orgânico em materiais biológicos e não biológicos (Akagi e Nishimura, s.d.); Mercúrio orgânico e mercúrio inorgânico combinados, em pequenas concentrações (Chilov, 1975). 


\subsection{Técnicas de descontaminação de efluentes do cianeto}

$\mathrm{Na}$ literatura especializada já se encontra um número considerável de publicações dedicadas às técnicas que visam a degradação dos cianetos e derivados, seja através das vias naturais (Schmidt et al., 1981; Resnick et al., 1958; Howe, 1965; Knowles, 1976; Thompson e Gerteis, s.d.; Knowles e Bunch, 1986; Ludzack e Schaffer, s.d.; Raff et al., 1977; Pettet e Mills, 1954; Mikami e Misono, 1968; Castric e Strobel, 1969; Alen e Strobel, 1966) seja através das induzidas (Costa, 1991; Montgomery et al., 1969), ou ainda, analisando-se por outro ângulo, as duas vias se intercomplementando (veja-se, como exemplos os trabalhos de Granato, 1986; 1993; Granato, et al., s.d.; Scott e Ingles, 1981).

Alguns autores preferem ainda considerar a chamada via natural da degradação de efluentes contendo cianetos como sendo, na verdade, duas vias. Uma delas recebe a denominação de via natural mesmo. A outra, denominada por biológica, "consiste na utilização"... "de organismos vivos (bactérias, fungos, algas ou macrófitas) que possuam a capacidade de metabolizar ou transformar os íons tóxicos, produzindo outros compostos, como amônia ou nitratos, ou decompô-los completamente, incorporando os átomos de carbono e nitrogênio liberados à sua biomassa", (Granato, idem; Granato, et al., idem). Por sua vez, o processo de degradação biológica é tido como ocorrendo por duas maneiras: aeróbia e anaeróbia. Respectivamente, com a presença ou a ausência do oxigênio.

O papel atribuído às bactérias na eliminação do cianeto está baseado nas suas necessidades metabólicas (alimentação/crescimento/reprodução): Os metais complexados com o cianeto são requeridos em certas concentrações por estes microorganismos. $\mathrm{Na}$ presença destes complexos de variadas concentrações as bactérias comportam-se de várias maneiras segundo as suas necessidades. Ainda que necessários, alguns metais, em altas concentrações provocam o desencadeamento de mecanismos de defesa a estes excessos. Um destes mecanismos pode representar transformação química destes compostos a uma forma menos tóxica. De outra maneira, um certo "isolamento" destes compostos na superfície celular (mecanismo de adsorção) ou na combinação destes com outros elementos produzidos pelas próprias bactérias também facilitam a remoção dos cianetos. É interessante observar que, sendo o mecanismo de adsorção um fenômeno que ocorre mesmo sem a participação ativa das bactérias (sem consumo energético do seu metabolismo), o mesmo verifica-se em presença de bactérias mortas. No caso da ação desempenhada por fungos, sabe-se que alguns possuem substâncias capazes de transformar compostos tóxicos de cianetos em outros não tóxicos.

A outra forma de degradação de efluentes chamada de natural consiste em deixar os rejeitos originados nas usinas confinados em barragens por um período, sem que haja qualquer intervenção humana para acelerar o processo (Granato, 1993). Esta etapa, onde ocorre o fenômeno denominado por volatilização, é responsável pela eliminação de grande parte do cianeto das soluções. O balanço entre a forma molecular $(\mathrm{HCN})$ e a livre $(\mathrm{CN})$ do cianeto é regida basicamente pelo $\mathrm{pH}$ da solução, ao passo que a volatilização propriamente dita é influenciada principalmente pela temperatura, aeração e a ação dos raios solares incidentes.

As vias ditas não naturais a que se recorre para a degradação do cianeto apresentam custos operacionais mais elevados por conta do emprego de aditivos químicos e técnicas físicas 
(mecânicas, elétricas). Exemplo disto é o emprego do hipoclorito de sódio. Testes em laboratório apontaram resultados plenamente satisfatórios na degradação dos cianetos de cobre, zinco e de cádmio, enquanto que outros complexos de cianetos mostraram-se resistentes ao tratamento. Os de maiores resistências foram os de ferro e os de prata (Costa, 1992). Também utiliza-se nestes tipos de tratamento o peróxido de hidrogênio, o qual é apontado como vantajoso ao anterior pelo aspecto de não deixar subprodutos tóxicos.

Estes modelos explicativos por vezes não representam bem os fenômenos analisados. Se for considerado o que ocorre, realmente, na intimidade - (bio)química - da degradação, se perceberá que as diversas etapas mencionadas podem ser intercomplementares, ou simultâneas. Conforme observado para o erro metodológico da divisão entre fenômenos da via natural e da induzida, o mesmo é aplicável à pretensa divisão entre as vias naturais e biológicas, ou também entre a aeróbia e a anaeróbia. Por exemplo, durante uma leitura sobre os modelos explicativos do que estaria ocorrendo ao nível da via aeróbia e da anaeróbia, pode-se constatar que em alguns casos a etapa anaeróbia é facilitadora, ou mesmo propiciadora, da aeróbia.

Há também os experimentos que visam conhecer os efeitos dos cianetos e derivados sobre as formas vivas. Um deles é o trabalho que trata da influência de compostos de cianeto sobre peixes (Doudoroff, 1956). Os autores realizaram medições de toxicidade para peixes com cianeto de sódio, cianeto de zinco, complexos de cianetos de cádmio, formas livres de cianeto combinadas com íons de níquel, niquelocianeto de sódio e íons ferricianeto.

\subsection{Novos avanços na investigação da lixiviação do ouro}

Diversas instituições de pesquisas estão financiando programas de estudos sobre a substituição do cianeto na lixiviação do ouro. Dentre alguns destes trabalhos já publicados citase o de Trindade (1994). O autor realizou um levantamento das publicações mais importantes sobre o uso da tiouréia do bromo para a dissolução do ouro. Além da revisão bibliográfica o autor faz uma discussão dos aspectos químicos e termodinâmicos destes processos, bem como apresenta as vantagens e desvantagens do uso destas substâncias em relação ao cianeto. No quadro em seguida são apresentados estes dados comparativos segundo o autor. 
Quadro 2 - Vantagens e desvantagens do emprego de tiouréia em relação ao cianeto e do bromo em relação ao cianeto e à tiouréia na lixiviação do ouro.

\begin{tabular}{|c|c|c|}
\hline \multicolumn{2}{|r|}{ Tiouréia } & Bromo/Brometo \\
\hline \multirow{5}{*}{$\begin{array}{l}\mathrm{V} \\
\mathrm{A} \\
\mathrm{N} \\
\mathrm{T} \\
\mathrm{A} \\
\mathrm{G} \\
\mathrm{E} \\
\mathrm{N} \\
\mathrm{S}\end{array}$} & $\begin{array}{l}\text { 1) As taxas cinéticas são cerca de } 10 \\
\text { vezes mais elevadas que no processo } \\
\text { convencional de cianetação }\end{array}$ & 1) Apresenta taxas de dissolução altas \\
\hline & $\begin{array}{l}\text { 2) O consumo de tiouréia na presença } \\
\text { de metais como cobre e ferro tende a } \\
\text { ser bem menor do que o cianeto }\end{array}$ & $\begin{array}{l}\text { 2) Não é excessivamente tóxico (embora o } \\
\text { manuseio do bromo em si exija certos cuidados) }\end{array}$ \\
\hline & 3) Tiouréia não é um reagente tóxico & $\begin{array}{l}\text { 3) Pode ser operado em larga faixa de } \mathrm{pH} \text { (neutro } \\
\text { a ácido) e, portanto, útil em situações onde o uso } \\
\text { do cianeto demande a neutralização do material } \\
\text { alvo }\end{array}$ \\
\hline & $\begin{array}{l}\text { 4) Vários elementos e compostos } \\
\text { podem ser usados em processos de } \\
\text { oxidação da tiouréia essenciais (íon } \\
\text { férrico, } \mathrm{O}_{2} \text {, hipoclorito, } \mathrm{H}_{2} \mathrm{O}_{2} \text { ) }\end{array}$ & $\begin{array}{l}\text { 4) Gera efluentes de menor risco ao meio } \\
\text { ambiente }\end{array}$ \\
\hline & $\begin{array}{l}\text { 5) Alguns minérios refratários podem } \\
\text { ser suscetíveis à lixiviação c/ tiouréia } \\
\text { (s/ alta recuperação certa de Au) }\end{array}$ & \\
\hline $\begin{array}{l}\text { D } \\
\text { E } \\
\text { S } \\
\text { V }\end{array}$ & $\begin{array}{l}\text { 1) O emprego da tiouréia demanda um } \\
\text { cuidadoso controle de pH, da } \\
\text { concentração do reagente e do } \\
\text { potencial redox da solução }\end{array}$ & $\begin{array}{l}\text { 1) O emprego do bromo está ainda longe de ter } \\
\text { aceitação industrial e sobrepujar o } \\
\text { desenvolvimento tecnológico que acompanha o } \\
\text { processo de cianetação }\end{array}$ \\
\hline $\begin{array}{l}\mathrm{A} \\
\mathrm{N} \\
\mathrm{T}\end{array}$ & & $\begin{array}{l}\text { 2) Os custos agregados ao bromo precisam ainda } \\
\text { ser comparados aos do cianeto }\end{array}$ \\
\hline $\begin{array}{l}\text { A } \\
G\end{array}$ & & $\begin{array}{l}\text { 3) A recuperação do ouro de soluções contendo } \\
\text { bromo precisa ser ainda equacionada }\end{array}$ \\
\hline $\begin{array}{l}\mathrm{E} \\
\mathrm{N} \\
\mathrm{S}\end{array}$ & & $\begin{array}{l}\text { 4) Os aspectos químicos envolvidos no processo } \\
\text { precisam ser ainda estudados em maiores } \\
\text { detalhes }\end{array}$ \\
\hline
\end{tabular}

\section{Tendências para o setor mineral}

Quanto à preocupação de se identificar tendências para os ditos setores formal e informal talvez fosse o caso de se falar, não numa substituição da garimpagem pela mineração industrial por conta da dimensão geográfica e da complexidade da rede social envolvida mas, sim, uma maior expansão do setor formal.

O primeiro aspecto a ser considerado nesta suposição é de ordem política e tecnológica. Há uma dificuldade patente do garimpeiro continuar a extração quando o ouro de aluvião dá sinais de esgotamento (inviabilidade técnica, na verdade) pois, como foi visto, para a imensa maioria são inacessíveis os meios de produção. Para se atingir os veios mais profundos é necessário adequar ao trabalho uma tecnologia mais arrojada. Motores em geral para gerar eletricidade e levar iluminação e aeração às galerias, ou para acionar os moinhos trituradores, bem como os processos de dinamitação das rochas, mostram-se quase sempre necessários na continuidade dos trabalhos. Ainda com relação aos recursos tecnológicos, busca-se a cianetação como alternativa à exploração tradicional do ouro aluvionar através do mercúrio. Com a montagem de uma planta hidrometalúrgica à base de cianeto torna-se possível a 
extração de ouro fino presente nos rejeitos, ou mesmo numa nova jazida (caso do Igarapé Bahia explorado pela Companhia Vale do Rio Doce). Este recurso está geralmente restrito às empresas mineradoras, pois o trabalho realizado por conta dos garimpeiros fica impossibilitado por serem os mesmos em sua imensa maioria descapitalizados. Quando não o são, recorrem às instituições públicas ou empresas de consultoria para assessorá-los na exploração dos rejeitos. Outro aspecto a ser considerado seria de ordem político-institucional. Segundo informações pessoais de técnico do DNPM, a legislação do setor mineral passou a limitar a área de ação dos garimpeiros no que se refere ao aprofundamento no subsolo e a classificar a garimpagem como atividade complementar à mineração industrial.

Conforme comentado anteriormente a maioria dos estudos que buscam desvendar os mecanismos de produção do metilmercúrio no meio ambiente estão baseados em experimentos de regiões do exterior e/ou corroborados por estudos laboratoriais. Estudos buscando modelos adequados, ou aprofundamento sobre o que já se investigou, para os ambientes dos trópicos úmidos também são necessários para se pensar um novo modelo de desenvolvimento para a Amazônia. O estudo sobre a origem e a mobilização do metilmercúrio frente às condições climáticas próprias da região favorece o entendimento de como ocorre a contaminação deste em populações ribeirinhas. Trabalhos que investigaram algumas destas populações contaminadas, embora não expostas ocupacionalmente, atribuíram a alimentação rica em peixes como a via de entrada. Além dos peixes, outros organismos aquáticos que possam servir de alimento também deveriam ser incluídos nestes estudos.

No caso do cianeto, os órgãos estatais responsáveis pela defesa do meio ambiente, através do controle da poluição e fiscalização das atividades industriais ou de quaisquer outras que provoquem impactos sócio-ambientais, têm um raio de ação limitado às análises de projetos em sua concepção original, aos textos complementares, ou através de RIMA (Relatório de Impacto do Meio Ambiente), ou, quiçá, ao acompanhamento periódico das atividades de rotina no local de processamento. Como se pode verificar na descrição sumarizada das técnicas de análises dos cianetos no CETEM/CNPq, as mesmas são viáveis para a análise e determinação dos cianetos em amostras na forma líquida, fato que atualmente impossibilita um trabalho seguro de gerenciamento ambiental. Na prática, tendo-se o campo de amostragem restrita aos meios líquidos, basicamente efluentes industriais, as estruturas sólidas adjacentes às áreas de cianetação ficam de fora do universo de amostragem, embora resíduos sólidos possam ser tratados através das atividades microbiais, conforme já comentado.

\section{Referências bibliográficas}

AKAGI, Hiroshi; NISHIMURA, Hajime. Speciation of Mercury in the Environment. s/e; p. 53-73, s.d.

ALLEN, J; STROBEL, G. The assimilation of $\mathrm{H}^{14} \mathrm{CN}$ by a Variety of Fungi. Canadian Journal of Microbiology, 12, p. 414-416; Montana Agricultural Experiment Station. USA, 1966.

AMORAS, Walter Wanderley. A Garimpagem na Amazônia: Doença, Desordem e Descaso; Uma visão do garimpo Crepori (PA). Belém; 306 ff. Dissertação de Mestrado. Universidade Federal do Pará - Plades, 1991.

BARBOSA, A. C. Contaminação por mercúrio em ribeirinhos e peixes do rio Madeira (RO) e em indios Kaiapo do sul do Pará. Departamento de Química, Universidade de Brasília. Cópia, s.d. 
BRABO, Edilson da Silva. Contaminação por mercúrio dos rios Crepori e Marupá - Bacia do Tapajós Pará. Belém; 116 ff. Dissertação de Mestrado. Universidade Federal do Pará - Centro de Geociências, s.d.

CAMPE, N; CLAEYS, A. Semi-Automated Determination of Mercury in Fish. Atomic Absoption Newsletter, 17(2), p. 37-41. University of Ghent, Belgium, 1978.

CASTRIC, P. AJ; STROBEL, G. Cyanide Metabolism by Bacillus megaterium. The Journal of Biological Chemistry; 244(15), p. 4089-94; Montana State University; Montana, USA, 1969.

CETESB. Água - Determinação de Mercúrio Total: Método de Espectrofotometria de Absorção Atômica - Gerador de Vapor a Frio; Método de Ensaio. s/e; s/l. p. 7, 1989.

CHAVES, A.. P; ALBUQUERQUE, G.S. Garimpo na Amazônia; Um problema que pode ter solução. Brasil Mineral, (118):48-51; s/1, 1994.

CHILOV, S. Determination of Small Amounts of Mercury. Talanta Review; 205-232. Research Laboratory, Kodak; Australia. 1975.

CLEARY, David. Gold mining and mercury use in the Amazon basin. Appropriate Technology, Vol. 17, NO 2(sept.), p. 17/19, 1990.

CLEARY, David. A garimpagem do ouro na Amazônia: Uma abordagem antropológica. Tradução de Virgínia Malm (Anatomy of the Amazon Gold Rush, 1990). Divisão gráfica da Universidade Federal do Rio de Janeiro, 1르 edição brasileira. 237 p., 1992.

COMPANHIA Vale do Rio Doce; Jaakko Pöyry Engenharia Ltda. Estudo de Impacto Ambiental; Projeto Ouro - Igarapé Bahia; Parauapebas - Pará. Volume 1, 1990.

COUTO, Rosa Carmina de Sena. Condições de saúde nos garimpos de ouro da Amazônia. p. 54/69. In: HACON. S; LACERDA, L. D.; PFEIFFER, W. C.; CARVALHO, D. (org.). Riscos e Conseqüências do Uso do Mercúrio. Anais do Seminário Nacional em Brasília, de 12 a 16/05 de 1989. FINEP - Rio de Janeiro. 314 p. ilust., 1992.

COUTO, Rosa Carmina de Sena.; CÂMARA, Volney M.; SABROZA, Paulo Chagastelles. Intoxicação mercurial: resultados preliminares em duas áreas garimpeiras no Estado do Pará. Pará Desenvolvimento, № 3(jan./jun.), p. 63/67. Belém, 1988.

COSTA, Antônio Carlos A.. Degradação de Cianetos por Hipoclorito de Sódio. Série Tecnologia Mineral, № 60; CETEM/CNPq; Rio de Janeiro. 44 p., 1991.

D'ITRI, Frank M. The Environmental Mercury Problem. The Chemical Rubber Co. Press; Clevelan, Ohio. 124 p., 1970.

DOUDOROFF, P. Some experiments on the toxicity of complex cyanides to fish. Sewage Ind. Wastes, 28 (8):1020-40, Oregon, 1956.

DOUDOROFF, P; KATZ, M. Critical Review of Literature on the Toxity of Industrial Wastes and Their Components to Fish; II. The Metals, as Salts. In: Industrial Wastes. Sewage and Industrial Wastes; 25(27), p. 802-839. Federation of Sewage and Industrial Wastes Associations; Ohio. USA., 1953. 
FERNANDES, Roosevelt da Silva.; GUIMARÃES, Austregésilo Ferreira.; BIDONE, Edison Dausacker. Monitoramento do mercúrio na área do Projeto Carajás. p. 37/44. s/e, s/l; fotocópia, s/d.

FORSBERG, B. R. Complementação de proposta para o projeto "Mercúrio no Meio Ambiente", solicitado pela Fundação Banco do Brasil. Manaus. Departamento de Ecologia. INPA, s/d.

GRANATO, Marcus. Metalurgia extrativa do ouro. Ministério da Minas e Energia. Centro de Tecnologia Mineral - CETEM. Brasília. Série Tecnologia Mineral Nº 37; Seção Met. Extrativa n. 14, 1986.

GRANATO, Marcus. Tratamento biológico de efluente proveniente do processo de cianetação de ouro, para degradação de cianeto e tiocianato e remoşão de metais pesados. Rio de Janeiro. Universidade Federal do Rio de Janeiro. Dissertação de Mestrado. 96 p., 1993.

GRANTO, Marcus; MACHADO, Márcia, M; COSTA, Antônio, C. A. Método de Destruição de Cianetos para Controle Ambiental em Areas de Mineração/Metalurgia do Ouro. Centro de Tecnologia Mineral - CETEM/CNPq. Rio de Janeiro. 11 p., s/d.

HACON, S; LACERDA, L; PFEIFFER, W; CARVALHO, C; (Orgs.). Seminário "Riscos e conseqüencias do uso do mercúrio"; 1989, Brasilia. FINEP, Rio de Janeiro. 314 p. ilust., 1990.

HOWE, Robert. H. L. Bio-Destruction of Cyanide Wastes - Advantages and Disadvantages. Int. J. Air Wat. Poll. Pergamon Press; 9:463-478. Great Britain, 1965.

INGLES, J. C. and SCOTT, J. S. Overvien of Cyanide Treatment Methods, Cyanide and Gold Seminar, Jan; Ottawa, Canada, 1981.

JOHNSON, W.C; GAGE, J.C; GORSUCH, T.T; JOHNSON, E.I; JOHNSON, E.M; MILTON, R.F; NEWMAN, E.I; SHARPLES, W.G; THACKRAY; TYLER, J.F.C; SHALLIS, P.W. The Determination of Small Amounts of Mercury in Organic Matter. The Analyst, 90(1074), p. 515-30. s/1, 1965.

KNOWLES, C. J. Microorganisms and Cyanide. Bacteriological Reviews; 40(3), p. 652-680; American Society for Microbiology; Kent, Great Britain, 1976.

KNOWLES, C. J; BUNCH, A. W. Microbial Cyanide Metabolism. Advances in Microbial Physiology; 27, p. 74-111; Academic Press, London, 1986.

LACERDA, L. D. Distribuição e comportamento de mercúrio no ambiente Amazônico; p. 8090. In: HACON, S; PFEIFFER, W.C.; LACERDA, L. D.; CARVALHO, D. (org.). Riscos e conseqüências do uso do mercúrio. Anais do Seminário Nacional em Brasília, de 12 a 16 de maio de 1989. FINEP - Rio de Janeiro. 314 p., 1992.

LINDSTEDT, G. A Rapid Method for the Determination of Mercury in Urine. Analyst, 95, p. 264-71; s/e; s/1, 1970.

LODENIUS, Martin. Mercury Contamination in the Tucurui Reservoir, Brazil. Departament of Limnology and Environmental Protection. University of Helsinki. Helsinki, Finland, p 43/48, 1992.

LOULE, Hon Way. Determination of Tota Mercury in Fish: An Improved Method. Australia Governamental Analytical Loboratories. Australia, 1983. 
LUDZACKJ, F. J; SCAHFFER, R. B. Activated Sludge Treatment of Cyanide, Cyanate and Thiocyanate. N. 22, p. 439-460. U.S. Public Health Service; Ohio, s/d.

MAGOS, L. Selective Atomic Absorption Determination of Inorganic Mercury and Methylmercury in Undigsted Biological Samples. Analyst, 96:847-53; s/1, 1973.

MAcMILLAN, Gordon J. Gold Mining and Land-Use Changes in the Brazilian Amazon. Universidade de Edinburgh; Grã-Bretanha. Tese de Doutorado, 264 p., 1993.

MARINS, R. S. Determinação de Cianeto Total. Centro de Tecnologia Mineral; Departamento de Química Analítica e Instrumental; Serviço de Análise Ambiental. Rio de Janeiro. Apostila, s/d.

- Uso da Medida Volumétrica na Determinação de Cianeto Livre para Monitoramento e Controle de Processos de Cianetação de Minérios Auriferos. Centro de Tecnologia Mineral CETEM/CNPq, Rio de Janeiro. Apostila, 1989.

. Determinação de Tiocianato em Águas Naturais e Efluentes; Metodologia Otimizada no DQI para o Projeto de Degradação de Cianetos por Bactérias (DBT/DME). Centro de Tecnologia Mineral - CETEM/CNPq, Rio de Janeiro. Apostila, 1990.

MARINS, R. S. Determinação de Cianeto Livre por Potenciometria Direta; Utilização do Eletrodo Seletivo a Cianeto. Relatório Técnico ao DME - Projeto Degradação Biológica de Cianetos/Regeneração de Cianetos. Centro de Tecnologia Mineral - CETEM/CNPq, Rio de Janeiro. Apostila, 1991.

MIKAMI, E; MISONO, T. Microbial Purification of Some Specific Industrial Wastes; (XI) Effect of Heavy Metal Ions on Cyanide Waste Treatment and Control of the Treatment with Cyano-Sensor. CJ. Ferment. Technol., 46(12), p. 1056-66; Fermentation Research Institute, Japan, 1968.

MONTGOMERY, H. A. C; GARDNER, Deider, K; GREGORY, J. G. G. Determination fo Free Hydrogen Cyanide in River Water by a Sovent-extraction Method. Analyst, 94, p. 284291. Crown Copyright. s/1, 1969.

OLIVEIRA, Evaldo Ferraz de.; CASTRO e SILVA, Edinaldo de.; OZAKI, Salete Kiyota. Mercúrio via cadeia trófica na Baixada Cuiabana: Ensaios preliminares. p. 202/210. In: HACON.S; LACERDA, L.D.; PFEIFFER, W.C.; CARVALHO, D. (org.). Riscos e Conseqüências do Uso do Mercúrio. Anais do Seminário Nacional em Brasilia, de 12 a 16/05 de 1989. FINEP - Rio de Janeiro. 314, 1992.

PETTET, A. E. J; MILLS, E. V. Biological Treatment of Cyanides, with and without Sewage; Biological Treatment of Cyanides. J. appl. Chem., (4), p. 434-444; s/1, 1954

PFEIFFER, W. C.; LACERDA, L. D. Mercury inputs into the Amazon region, Brazil. Environmental Technology Letters, 9:325-330. Publication Division Selper, Ltd., 1988

PFEIFFER, W.C.; LACERDA, L.D. de.; MALM, O.; SOUZA, C.M.M.; SILVEIRA, E.G. da.; BASTOS, W.R. Mercury concentrations in inland waters of gold mining areas in Rondônia, Brazil. The Science of the Total Environment. p. 233/240. Elsevier Science Publishers B.V. Amasterdam, 1989.

PFEIFFER, W. C; MALM, O; SOUZA, C. M; LACERDA, L. D; SILVEIRA, E. G. A ameaça do mercúrio nos garimpos. Ciência Hoje. SBPC. Vol. 11(61), p. 10-12, 1990. 
PROCESSOS E PROJETOS MINERAIS LTDA (PPM) Plano de Controle Ambiental (PCA) Mineração Capanema Ltda - Projeto Cachoeira, Vizeu - PA, 1993.

PICKARD, J.A; \& MARTIN, J.T. Determination of Mercury in Plant Material. J. Sci. Food Agric., 374-77; Long Ashton Research Station; University of Bristol, 1960.

RAMOS, J. F. Fonseca.; COSTA, Manoel Quaresma. Distribuição do mercúrio em dois garimpos do Estado do Pará. p. 70/79. In: HACON.S; LACERDA, L.D.; PFEIFFER, W.C.; CARVAlHO, D. (org.). Riscos e Conseqüências do Uso do Mercúrio. Anais do Seminário Nacional em Brasília, de 12 a 16/05 de 1989. FINEP - Rio de Janeiro. 314 p ilust., 1992.

RAFF, S. F; CHARACKLIES, W.G; KESSICH, M. A; WARD, C. H. Fate of Cyanide and Related Compounds in Aerobic Microbial Systems - I; Chemical Reaction with Substrate and Physical Removal. Water Reserach, 11, p. 477-483; Pergamon Press; Great Britain, 1977.

RAFF, S. F; CHARACKLIES, W.G; KESSICH, M. A; WARD, C. H. Fate of Cyanide and Related Compounds in Aerobic Microbial Systems - II; Microbial Degradation. Water Reserach, 11, p. 485-492; Pergamon Press; Great Britain, 1977.

RESNICK, J. D.; ALLAN MOORE, W.; ETTINGER, M. B. Behavior of Cyanates in Polluted Water. U.S. Public Health Service; 50(1), p. 71-72. Ohio, 1958.

SCHMIDT, J. W.; SIMOVIC, L.; SHANNON, E. Natural Degradation of Cyanides in Gold Milling Effluents. In: Cyanide and the Gold Mining Industry Seminar. Wasterwater Technology Center. Canada. 42 p., 1981.

SCOTT, J. S.; INGLES, J. C. Removal of Cyanide from Gold Mill Effluents. In: Thirteenth Anual Meeting of Canadian Mineral Processors; Paper № 21, p. 380-418. Mining an Metallurgical Division. Ontario; Canada, 1981.

SILVA, A. S.; GUIMARÃes, G. A.; COSTA, M. Q.; SOUZA, T. M. D. A contaminação mercurial nos garimpos de ouro da Amazônia. In: Anais do III Congresso Brasileiro de Defesa do Meio Ambiente. Rio de Janeiro, 1989.

THOMPSON, L. C; GERTEIS, R. L. New Technologies for Mining Waste Manegement; Gold Fields Mining Corporation; Colorado; Mining and Mineral Porcessing Wastes; 23(11), p. $271-278$, s/d.

THORNTON, Ian.; CLEARY, David.; WORTHINGTON, Simon. Mercury Contamination in the Brazilian Amazon. A Report for the Commission of the European Communities. SOL 3. s/l. 109 p., s/d.

TRINDADE, Roberto de B. E. Tiouréia e bromo como lixiviantes alternativos à cianetação do ouro. Série Tecnologia Mineral; № 67; CETEM/CNPq. Rio de Janeiro. 50 p., 1994.

THORNTON, I; CLEARY, D; WORTHINGTON, S. Mercury Contamination in the Brazilian Amazon. A Report for the Commission of the European Communities. SOL 3/GEDEBAM. 109 p., s/d.

VEIGA, Marcelo M. et al. Poconé: Um campo de estudos do impacto ambiental do garimpo. SérieTecnologia Ambiental, 1. CETEM/CNPq. Rio de Janeiro. 113 p., s/d. 
WORLD HELTH ORGANIZATION. Environmental Health Criteria,1. Mercury. Published by United Nations Environment Programme and WHO. Geneva, Switzerland. 131 p., 1976.

WORLD HEALTH ORGANIZATION. Environmental Health Criteria, 86. Mercury: Environmental Aspects. Published by United Nations Environment Programme, the International Labour Organization and WHO. Printed in Finland - Vammala. 115 p., 1989. 